\title{
EXPLORING AESTHETIC PREFERENCES IN RURAL LANDSCAPES AND THE RELATIONSHIP WITH SPATIAL PATTERN INDICES
}

\author{
EMMA SOY MASSONI ${ }^{1}$, DIEGO VARGA ${ }^{1}$, MARC SÁEZ $^{2,3}$, JOSEP PINTÓ $^{1}$ \\ ${ }^{1 *}$ Landscape Analyses and Management Laboratory. Geography Department, University of \\ Girona, Pl. Ferreter i Móra, 1. 17071 Girona, Spain, 003497241 8999, e-mail: \\ emma.soy@udg.edu; diego.varga@udg.edu; josep.pinto@udg.edu, *corresponding author \\ ${ }^{2}$ CIBER of Epidemiology and Public Health (CIBERESP), Spain \\ ${ }^{3}$ Research Group on Statistics, Econometrics and Health (GRECS), University of Girona. \\ Campus Montilivi, 17071 Girona,Spain,0034972418338,e-mail: marc.saez@udg.edu
}

Received: $9^{\text {th }}$ September 2015, Accepted: $28^{\text {th }}$ February 2016

\begin{abstract}
This study examines how local population, tourists and farmers relate to rural landscapes, by exploring visual landscape preferences and the influence of everyday landscapes on the research subjects. Results point towards an immense variability in visual landscape preferences amongst user groups living in or visiting the study area (Plana de l'Empordà, Girona, Spain). Tourists rate grasslands at the top of their preference list, local residents prefer orchards, and farmers favour fields of irrigated herbaceous crops; showing, altogether, that the user's relationship with the landscape determines their visual preferences. Results show that farmers prefer agriculture dominated scenes while local residents and tourists prefer scenes with equilibrium between agricultural and natural elements. Likewise, the presence of margins is widely appreciated aesthetically by all respondents. Furthermore, results underline the importance of landscapes that are familiar to the respondents.
\end{abstract}

\section{Highlights:}

- Surveys to explore visual landscape preferences were conducted on user groups.

- We used photos and aerial images of agricultural landscapes to support the questionnaires.

- We found differences towards aesthetic preferences across respondents groups.

- We found consensus for presence of margins among respondents.

- Certain importance of familiarity and respondents' attachment to place was found.

\section{INTRODUCTION}

Agricultural landscapes in the Mediterranean region have adopted a new socio-economic scenario (Claval, 2005), where agriculture is no longer the economic base of the local economy and farm managers make up a relatively small part of the population that either own or actively manage the land (Surová et al., 2011). Today, agricultural landscapes are everyday landscapes for many people and this is why these landscapes have to provide 
Soy-Massoni E., Varga D., Sáez M., Pintó J.: Exploring aesthetic preferences in rural landscapes and the relationship with spatial pattern indices

ecological as well as social functions (Buijs et al., 2006). This new socio-economic situation in a rural and agricultural context has an impact on the demand for landscape services and values from different stakeholders with varying interests. Different polices have recognized the key role of human perceptions and attitudes as the drivers of landscape change and preservation of sustainable landscapes, and as a component of determining appropriate land use policies (Pan-European Biological and Landscape Diversity Strategy (Council of Europe, 1996); European Landscape Convention (Council of Europe, 2000)).

In the management of many landscapes, great difficulty exists in reaching a consensus guaranteeing results to be environmentally sustainable, socially acceptable, easily comprehended and economically feasible (de Val et al., 2006). Sullivan et al. (2004) have demonstrated that conflicts appear when the visual appearance of a landscape opposes public preferences. Identifying specific cohorts of population with similarities in terms of landscape preferences will assist the development of general guidelines for landscape design (Strumse, 1996). Nowadays, the integration of people's preferences is a critical component of landscape planning (Lindemann-Matthies et al., 2010). It contributes to avoiding conflicts between opposing groups by encouraging landowners to manage farmland in a socially desired manner, through the introduction of incentives and mitigation measures in regional policies and landscape development instruments. The visual quality of landscape can be considered a key aspect for the interaction between people and landscape. A wide range of previous studies focusing on variation in social preferences towards aesthetic rural landscapes is available. For instance, people-place relationship appears to be a significant element influencing visual landscape preferences (Walker \& Ryan, 2008). But landscape preferences are not only influenced by physical characteristics such as the heterogeneity of landscape, they are also influenced by socio-demographic factors such as age, gender, formal education, familiarity and experience with a certain landscape type (Gobster et al., 2007), farming background (Van den Berg \& Koole, 2006) and people's environmental values (Howley et al., 2012). Visual preferences for landscapes are also influenced by feelings and imagination that landscape elements evoke in a viewer such as peacefulness and freedom (Nohl, 2001). Moreover, people might prefer familiar landscapes or landscape elements which they have experienced for some time, regard them as typical (Nohl, 2001; Van den Berg \& Koole, 2006), or depending on people's involvement, i.e. either active or passive (Buijs et al., 2006). Traditional farming landscapes seem to be more valued in terms of identity for local communities (Howley et al., 2012) and modern agricultural landscapes are associated with more homogeneous structures which are assumed to be visually less attractive (Hietala-Koivu, 1999). Land-cover structure plays a significant role in the visual quality of landscape (de Val et al., 2006).

This study examines how local population, tourists and farmers relate to rural landscapes, by exploring their visual landscape preferences and the influence of their everyday surrounding landscapes. The study approach develops the assessment of landscape aesthetics carried out by the general public, i.e. no experts or judgements (Misgrav, 2000). As photographs have been found to be acceptable surrogates of real vistas for the study of visual quality (Bergen et al., 1995; Bulut \& Yilmaz, 2008; Bulut \& Yilmaz, 2009), we used landscape photos as landscape surrogates and we conducted an analysis of the individuals' ratings of a variety of landscapes images.

Our goal is to provide better understanding and to account for the relationships between rural farming and non-farming populations, and tourists, and agricultural landscape through the lens of aesthetic preferences. The three specific objectives consist in: 1) the characterization of respondents, 2) visual landscape preferences regarding the most representative agricultural uses, 3) visual landscape preferences regarding different 
agricultural landscape structures and compositions, and 4) relationship between current living landscape and landscape preferences.

The study focused on the following questions:

1) Will aesthetic preferences differ among respondent groups (local residents, farmers and tourists) and among place characteristics?

2) Will consensus among respondent groups in terms of visual preferences be found for any given landscape use or landscape structures and compositions?

3) Will familiarity with types of landscape result in higher preferences for local residents (farmers and non-farmers)?

4) Will personal characteristics, such as age, gender and farming familiarity, play a significant role in explaining individual's preferences regarding rural landscapes?

5) Is the use of landscape photos and aerial images a good method to test aesthetic landscape preferences?

\section{METHODS}

\section{Study area}

The study was performed in the Plana de l'Empordà landscape unit, located in the north east of Girona, Spain (Figure 1). The area covers $415 \mathrm{~km}^{2}$ and has 132,168 inhabitants. The region has a typical Mediterranean climate, with an average precipitation of $474.4 \mathrm{~mm}$ per year and an average annual temperature of $14.7^{\circ} \mathrm{C}$.

Fig. 1: Study area Plana de l'Empordà, Costa Brava (Spain): Location, protected areas and sample points

Sample points
1 Rabós
2 Santa Llogaia d'Alguema
3 Viladamat
4 Pont de Molins
5 Vilabertran
6 L'Armentera
7 Llers
8 Avinyonet de Puigventós
9 Perlada
10 Vilafant
11 L'Escala
12 Castelló d'Empuries
13 Figueres
14 Roses beach
15 Aiguamolls Empordà
Natural park
16 Sant Pere Pescador
17 Vilamacolum
18 Fortià
19 Torroella de Fluvià
20 Siurana
21 Vilamalla
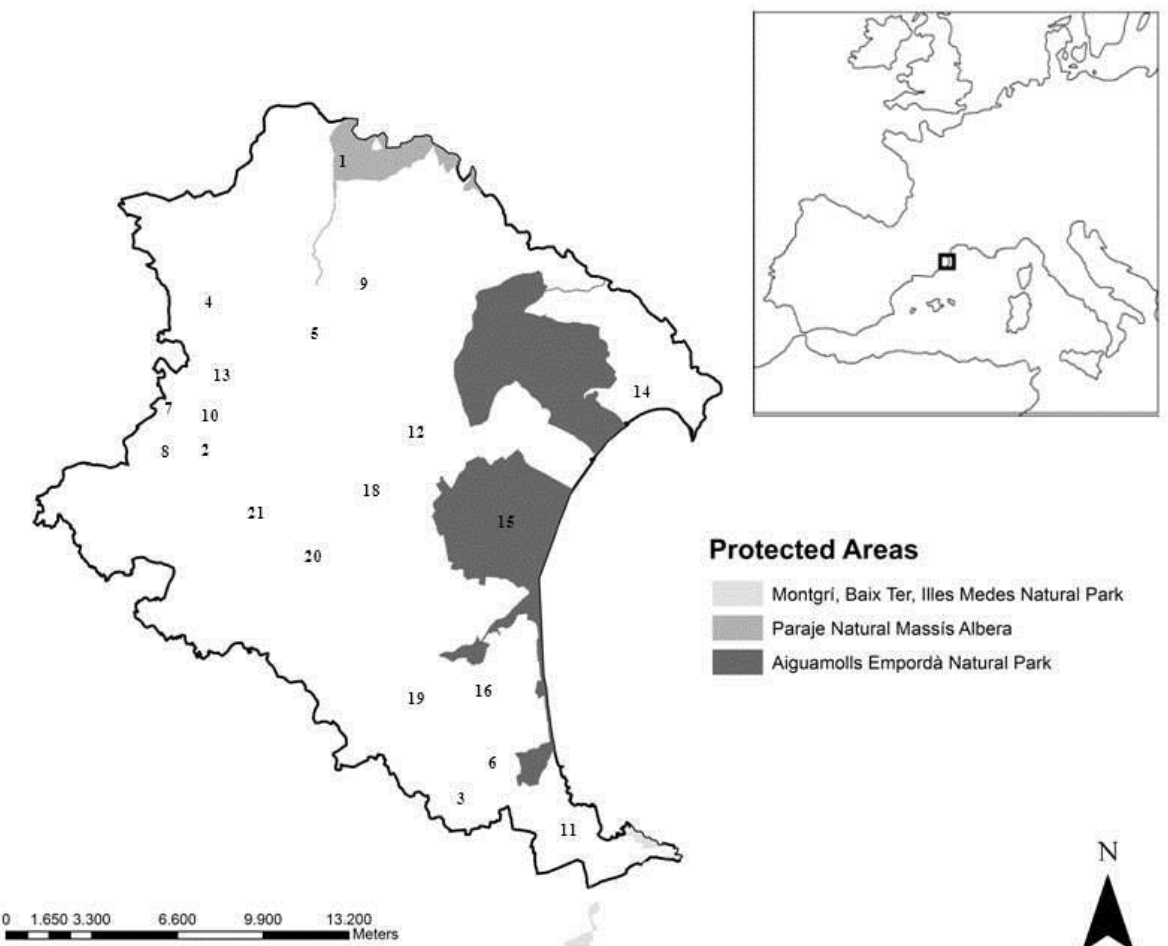

Protected Areas

Montgri, Baix Ter, Illes Medes Natural Park

Paraje Natural Massis Albera

Aiguamolls Empordà Natural Park 
Soy-Massoni E., Varga D., Sáez M., Pintó J.: Exploring aesthetic preferences in rural landscapes and the relationship with spatial pattern indices

The predominant feature of the landscape is growing crops (76.64\% of the study area), mostly irrigated herbaceous crops $(36.2 \%)$ and dry herbaceous ones $(33.2 \%)$; both of which occupy $69.8 \%$ of the agricultural area. Other crops found to a lesser extent are fruit trees $(5.7 \%)$, olives (Olea europea) $(4.4 \%)$, grapes (Vitis vinifera) $(3.8 \%)$, grasslands $(3.24 \%)$, horticulture $(1.16 \%)$, and nut trees $(0.11 \%)$. Agriculture is present on $318 \mathrm{~km}^{2}$ of land, but only $0.7 \%$ of the population is engaged in the agriculture sector (IDESCAT, 2013). The study area is a popular holiday and recreation destination, mainly on the coast but also the traditional structures of the villages are attractive for domestic and international tourists.

$14 \%$ of the study area is protected and includes Mediterranean mountains, wetlands, coastline and agricultural lands. The Aiguamolls de l'Empordà Natural Park (PNAE) is the largest protected area in the study area. Currently one the most visited natural parks in Catalonia, it was created in 1983 and is composed of a combination of wetlands and grasslands, known as "closes" (Llausàs et al., 2009).

\section{Data collection}

We conducted a face-to-face survey on 251 respondents at 21 different locations, including urban zones, rural villages, beaches and the Aiguamolls de l'Empordà Natural Park. The population sample included randomly selected local residents - non-farmers, local residents farmers and tourists. All respondents were at least 18 years old. The survey was conducted from March to May 2013 and the response rate of the surveys was 100\%.

The questionnaire was divided into three sections in line with the first three specific objectives: (1) socio-demographic information of the respondents, (2) aesthetic preferences in agricultural uses, and (3) aesthetic preferences in landscape structures and composition.

In the first section, we assessed the respondents' socio-demographic characteristics (e.g., age, gender, level of studies, profession, residency, origin, i.e. place they were raised).

In the second section, the aesthetic preferences in agricultural uses, respondents were asked to order agricultural uses from their aesthetic point of view, with 1 being the best and 8 the worst. We included the 8 agricultural uses occupying the majority of the surface in the study area (dry and irrigated herbaceous crops, grasslands, fruit trees, olives, grapes, nut trees and horticulture) (Figure 2). This section addressed the following question: "Can you please order your aesthetic preferences towards these crops landscapes from the best to the worst in terms of beauty?"

And, in the third section, respondents were asked to aesthetically value six pairs of two opposing agricultural landscape structures or compositions: crop dominated landscape versus forest dominated landscape, small crop plots versus large crop plots, regular plots versus irregular plots, monoculture landscapes versus crop diversity landscapes, presence of margins versus no margins, and shade of green landscapes versus shade of brown landscapes (Figure 3). In the case of crop dominated versus forest dominated and shade of green versus shade of brown, we also included a balance between crop and forest and a balance between shade of green and shade of brown. The balance options were not present in photos. The aesthetic valuation attempted to capture which agricultural landscape structures or compositions respondents preferred between a pair of opposite scenes; and the question formulated to the respondents was the following: "What landscape do you prefer in terms of aesthetics and beauty between these two (or three) landscape options (e.g. a landscape dominated by crops, a landscape dominated by forest, or a landscape in balanced between forest and crop)?". 
Fig. 2: Landscape photographs used in the survey and presenting different agricultural uses (a-dry herbaceous crops, b-irrigated herbaceous crops, c-grasslands, d-fruit trees, e-olives, f-grapes, g-horticulture and h-nut trees).
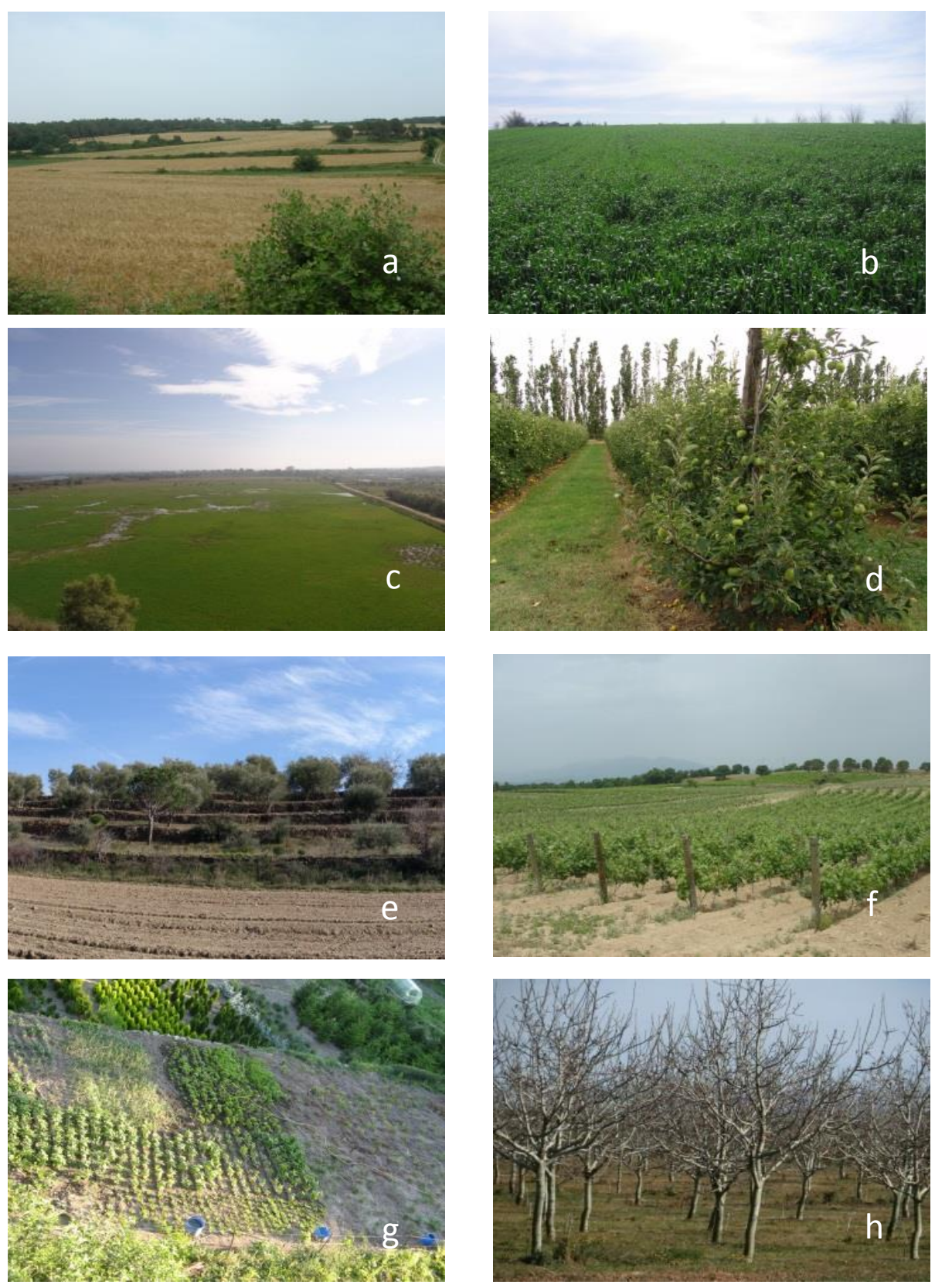

We used photos and aerial photography (Google Maps), both in colour, to support the questionnaires (Figures 2 and 3). Photos were taken at the same time of the year (winter). 
Soy-Massoni E., Varga D., Sáez M., Pintó J.: Exploring aesthetic preferences in rural landscapes and the relationship with spatial pattern indices

Fig. 3: Aerial images used in the survey presenting different landscape structures and compositions

(a-forest dominated , b-crop dominated , c-small crop plots, d-large crop plots, e-regular plots, f-irregular plots, g-monoculture, h-diversity of crops, i-presence of margins, $j$-absence of margins, $\mathrm{k}$-shade of green, 1-shade of brown)
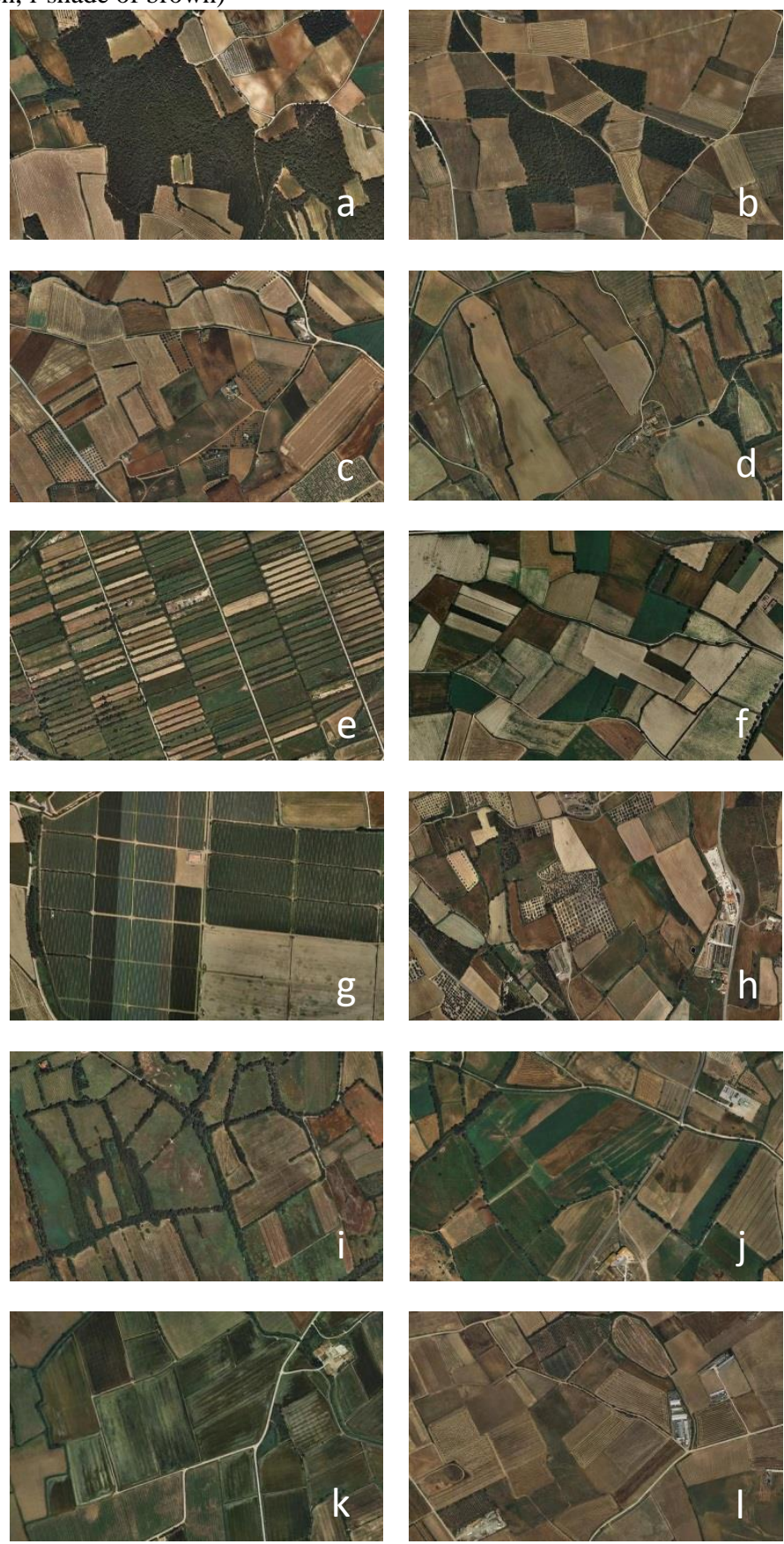
In order to test how current living landscape affects landscape preferences (Objective 4), we collected landscape data from the respondent's municipality, although only in the local residents (farmers and non-farmers) cases. For each municipality included in the sample we calculated 10 landscape pattern indices which have a relationship with the data collected through the interviews:

- $\quad$ area occupied by each agricultural use

- percentage of forest surface, percentage of crop surface, forest-crop surface relationship

- mean size of agricultural plots

- mean shape index of agricultural plots,

- $\quad$ landscape Shannon index and landscape dominance index

- margins surface

- $\quad$ dry vs. irrigated herbaceous crop surface ratio

Land-cover maps of the regions were used to calculate landscape metrics (Sigpac, 2012), and we used FRAGSTATS software (McGarigal \& Marks, 1994) for Shape index, Shannon index and Dominance index calculations (for all formulae see McGarigal \& Marks, 1994).

\section{Data analysis}

On assessing the relationships between user groups (locals, tourists and farmers) and rural landscapes we used generalized linear models (GLM) (McCullagh \& Nelder, 1989).

$$
\begin{aligned}
& E(Y \mid X)=\mu \\
& g(\mu)=X \beta \\
& \operatorname{Var}(Y)=\phi v(\mu)
\end{aligned}
$$

Where Y denotes the dependent variable, whose (conditional) expectation is equal to $\mu$; $\mathrm{X}$ is the matrix of explanatory variables (including an intercept); and $\beta$ and $\phi$ are unknown parameters. The parameter $\phi$ is also known as the 'dispersion' parameter. The function $\mathrm{g}($.$) is$ known as 'link function' and v(.) the 'variance function'. These functions depend on the nature of the dependent variable.

When the dependent variable was quantitative and discrete (agricultural uses) a Poisson model was used, i.e. a logarithmic link and identity variance function.

$$
\begin{aligned}
& E(Y \mid X)=\mu \\
& \log (\mu)=X \beta \\
& \operatorname{Var}(Y)=\phi \mu
\end{aligned}
$$

When the variable was dichotomous and qualitative (agricultural landscape structures and compositions) a binomial distribution was used, i.e. a logit link and a variance function as follows. 
Soy-Massoni E., Varga D., Sáez M., Pintó J.: Exploring aesthetic preferences in rural landscapes and the relationship with spatial pattern indices

$$
\begin{aligned}
& E(Y \mid X)=\mu \\
& \log \left(\frac{\mu}{1-\mu}\right)=X \beta \\
& \operatorname{Var}(Y)=\phi \mu(1-\mu)
\end{aligned}
$$

Models were estimated by penalized quasi likelihood (PQL).

All analyses were conducted using the free software R (version 3.0.3) (R Core Team, 2014).

\section{RESULTS}

\section{Characterization of respondents}

Most of the respondents (66.1\%) were middle-age adults (31-60); $24.7 \%$ originating from farming families, although only $4.6 \%$ of them stated they were still working in agriculture, while most respondents were employed in the service sector (65.7\%) (See Apendix 1). Of the respondents 24.5\% originated from the study area, 25.7\% from the wider Alt Empordà County, $15.8 \%$ from the Girona province, $25.3 \%$ from other parts of Catalonia and $8.7 \%$ from abroad (including other Spanish regions). We divided respondents into locals (respondents living within the study area), tourists (respondents living outside the study area), and farmers (respondents living within the study area working as farmers). From the 251 useful questionnaires, $36.25 \%$ were filled out by Tourists, $6.77 \%$ by Farmers and $56.97 \%$ by the Locals.

We divided the sample into seven classes of user groups depending on the sampling locations and whether they were locals or tourists. We considered the tourists encountered at the Aiguamolls de l'Empordà Natural Park as "park tourists", and the tourists met at the beach in Roses, as "beach tourists". Individuals found in Roses or Aiguamolls de l'Empordà Natural Park living in the study area were not included in the sample.. The user groups are as follows: (1) Tourists - Aiguamolls de l'Empordà Natural Park (18.32\%) - Park T; (2) Tourists - Roses beach - Beach T (17.92\%); (3) locals residents from villages of fewer than 2,000 inhabitants - L1 (33.86\%); (4) local residents from villages of 2,000-15,000 inhabitants -L2 (11.15\%); (5) local residents from towns of more than 15,000 inhabitants -L3 (11.95\%), and (6) farmers $-\mathrm{F}(6.77 \%)$.

\section{Aesthetic preferences in agricultural uses}

Respondents' perceptions based on how well they liked each of the landscape views regarding agricultural uses are shown in Table 1. The highest value, 3.55, was given to fruit trees, and the lowest value, 5.24, to nut trees and dry herbaceous crops. The favourite landscape views included fruit trees, grapes and olives; the least attractive views included nut trees, dry herbaceous crops and grasslands. The standard deviation in the responses ranged from 2.07 for grapes to 2.44 for horticulture. Table 2 shows a positive significant relationship between the visual grasslands preference and both types of tourists, between the irrigated herbaceous and farmers, and between fruit trees and locals (L2 and L3). It is also found that local population from the biggest towns and both types of tourists have a negatively significant relationship between their aesthetic preferences and olive landscape views. We found several socio-demographic factors influencing visual preferences towards 
agricultural uses. There is a positive significant relationship between age and the nut tree landscape view. It is significant that women prefer aesthetically dry herbaceous crops and grapes more than men, and the opposite for horticulture. We found a positive relationship between respondents coming from a farming family and preferences for olives and horticulture landscape views.

Table 1: Mean ranking of public preferences for landscape views and standard deviation in the responses $(n=251)$.

\begin{tabular}{|c|c|c|}
\hline Landscape view & Mean ranking & $\begin{array}{c}\text { Standard } \\
\text { Deviation }\end{array}$ \\
\hline Fruit trees & 3.55 & 2.08 \\
\hline Grapes & 3.81 & 2.07 \\
\hline Olives & 4.18 & 2.31 \\
\hline Horticulture & 4.48 & 2.44 \\
\hline Irrigated herbaceous & 4.61 & 2.21 \\
\hline Grasslands & 4.86 & 2.33 \\
\hline Dry herbaceous & 5.24 & 2.19 \\
\hline Nut trees & 5.24 & 2.09 \\
\hline
\end{tabular}

Table 2: Variables explaining respondent groups preferences regarding agricultural uses (-: negatively significant relationship; +: positively significant relationship).

L1: locals residents from villages of fewer than 2,000 inhabitants; L2: local residents from villages of 2,000-15,000 inhabitants; L3: local residents from towns of more than 15,000 inhabitants; F: farmers; Park T: Tourists - Aiguamolls de l'Empordà Natural Park; Beach T: Tourists - Roses beach. Farm relationship means if respondents came from a farming family.

\begin{tabular}{|c|c|c|c|c|c|c|c|c|c|}
\hline & L1 & $\mathrm{L} 2$ & L3 & $\mathrm{F}$ & Park T & Beach T & Age & Gender & $\begin{array}{l}\text { Farm } \\
\text { relation } \\
\text { ship }\end{array}$ \\
\hline Dry herbaceous crops & ref & & & & & & - & - & \\
\hline $\begin{array}{l}\text { Irrigated herbaceous } \\
\text { crops }\end{array}$ & ref & & & + & & & & & \\
\hline Olives & ref & & - & & - & - & - & & + \\
\hline Grapes & ref & & & & & & & - & - \\
\hline Fruit trees & ref & + & + & & & & - & & \\
\hline Nut trees & ref & & & & & & + & & \\
\hline Horticulture & ref & & & & & & - & + & + \\
\hline Grasslands & ref & & & & + & + & - & & - \\
\hline
\end{tabular}


Soy-Massoni E., Varga D., Sáez M., Pintó J.: Exploring aesthetic preferences in rural landscapes and the relationship with spatial pattern indices

\section{Aesthetic preferences in agricultural landscape structures and compositions}

Respondents' perceptions based on how well they liked each pair of landscape views regarding agricultural landscape structures or compositions are shown in Table 3. There is an equilibrium of visual preferences between forest dominated (35.06\%), crop dominated $(31.87 \%)$ and balanced forest/crop $(33.07 \%)$, and between small crop plots $(52.19 \%)$ and large crop plots $(47.81 \%)$. But visual preferences are much higher for irregular plot landscape views $(80.08 \%)$ than regular plot landscape views $(19.92 \%)$ and for diversity of crops $(86.06 \%)$ rather than monoculture $(13.94 \%)$. Presence of margins landscape views $(66.14 \%)$ are preferred to the absence of margins landscape views $(33.47 \%)$. Shade of green landscape view $(58.96 \%)$ and balanced $(29.48 \%)$ between shade green and shade brown are preferred to shade brown landscape view (11.16\%).

\section{Table 3: Preferences towards six pairs of two opposing agricultural landscape structures or composition views}

\begin{tabular}{|c|c|}
\hline Landscape view & \% \\
\hline Forest dominated & 35.06 \\
Crop dominated & 31.87 \\
Balanced & 33.07 \\
\hline Small crop plots & 52.19 \\
Large crop plots & 47.81 \\
\hline Regular plots & 19.92 \\
Irregular plots & 80.08 \\
\hline Monoculture & 13.94 \\
Diversity of crops & 86.06 \\
\hline Presence of margins & 66.14 \\
Absence of margins & 33.47 \\
\hline Shade of green & 58.96 \\
Shade of brown & 11.16 \\
Balanced & 29.48 \\
\hline
\end{tabular}

Table 4 show variables explaining respondent groups' preferences regarding agricultural landscape structures and compositions. It is significant that farmers prefer crop dominated landscapes to forest dominated landscapes; but locals from the biggest municipalities and park tourists prefer forest dominated landscapes. Only locals from the biggest municipalities significantly prefer small crop plot landscapes to big, and, together with park tourists, they prefer irregular plot landscape views to regular ones. We found a significant relationship between all respondent groups and visual preferences regarding the presence of margins, meaning that there is a large consensus that the presence of margins is aesthetically preferred over absence of margins. It is significant that medium size municipality respondents and park tourist respondents prefer the shade of green landscape views to the shade of brown. Age is the only socio-demographic variable with significant relationship with visual preferences for agricultural landscape structures or composition landscape views. Younger respondents prefer forest dominated views and older respondents prefer crop dominated ones. 
Table 4: Variables explaining respondent groups preferences regarding agricultural landscape structures and compositions (: negatively significant relationship; +: positively significant relationship).

L1: locals residents from villages of fewer than 2,000 inhabitants; L2: local residents from villages of 2,000-15,000 inhabitants; L3: local residents from towns of more than 15,000 inhabitants; F: farmers; Park T: Tourists - Aiguamolls de l'Empordà Natural Park; Beach T: Tourists - Roses beach.

\begin{tabular}{|l|c|c|c|c|c|c|c|}
\cline { 2 - 8 } \multicolumn{1}{c|}{} & L1 & L2 & L3 & F & Park T & Beach T & Age \\
\hline Forest dominated & ref & & & & & & - \\
\hline Crop dominated & ref & & - & + & & - & + \\
\hline Small crop plots & ref & & + & & & & \\
\hline Large crop plots & ref & & - & & & & \\
\hline Regular plots & ref & & - & & - & & \\
\hline Irregular plots & ref & & + & & + & & \\
\hline Monoculture & ref & & & & & & \\
\hline Diversity of crops & ref & & & & & & \\
\hline Presence of margins & ref & + & + & + & + & + & \\
\hline $\begin{array}{l}\text { No presence of } \\
\text { margins }\end{array}$ & ref & - & - & - & - & - & \\
\hline Shade of green & ref & + & & & + & & \\
\hline Shade of brown & ref & - & & & - & & \\
\hline
\end{tabular}

\section{Relationship between current living landscape and landscape preference}

We tested how current living landscapes of local residents (farmers and non-farmers) influence their expressed aesthetic preferences to agricultural uses and agricultural landscape structures and composition. Only the presence of irrigated herbaceous crops and olives in the familiar landscape of locals and farmers has a significant influence on their aesthetic preferences towards these agricultural uses, in this case both positively (Table 5).

Higher dominance index in the landscapes of locals and farmers' municipalities has a negative significant influence on their aesthetic preferences towards the crop dominated landscape view (Table 6). Municipalities with greater forest and margin coverage have a positive significant influence on aesthetic preferences towards shade of green landscape view of the respondents (Table 6). 
Soy-Massoni E., Varga D., Sáez M., Pintó J.: Exploring aesthetic preferences in rural landscapes and the relationship with spatial pattern indices

Table 5: Relationship between preferences towards agricultural uses landscape view and cover $(\%)$ of each agricultural use in the municipality of local residents and farmers $(\mathbf{p}<0.05)$

(-: negative significant relationship; +: positive significant relationship).

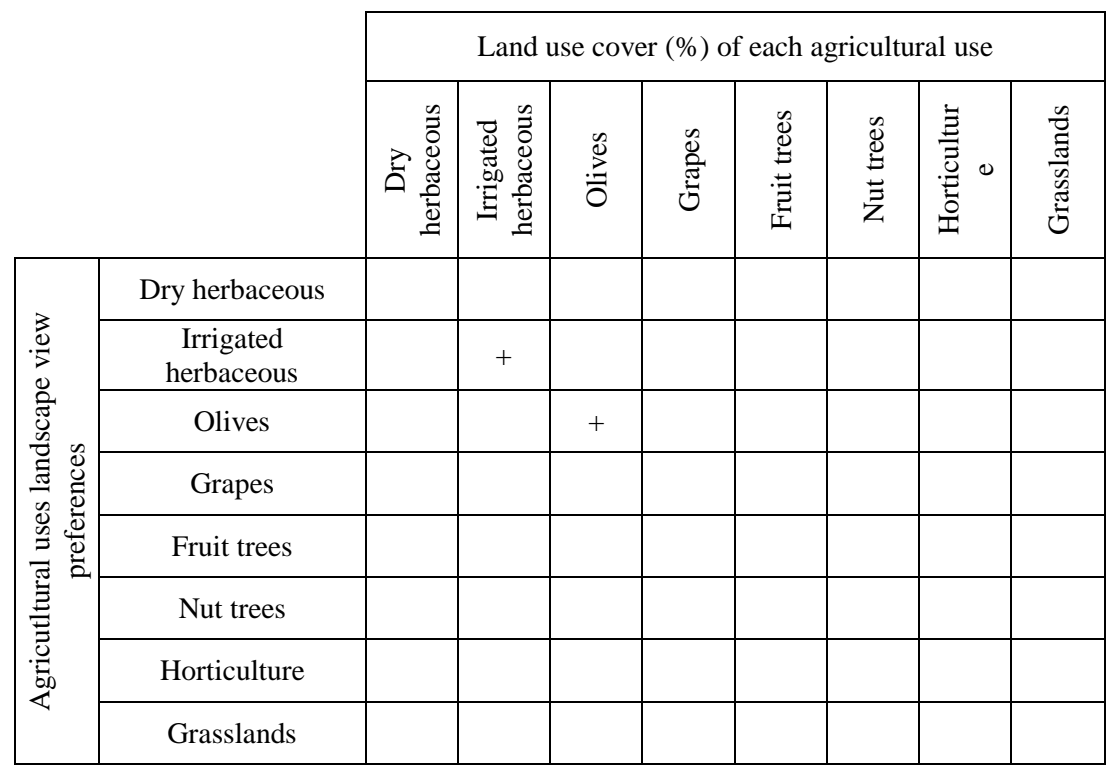

Table 6: Relationship between preferences towards agricultural landscape structures or composition landscape views and landscape indexes in the municipality of local residents and farmers $(p<0.05)$

(-: negative significant relationship; +: positive significant relationship).

\begin{tabular}{|c|c|c|c|c|c|c|c|}
\hline & 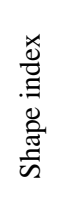 & 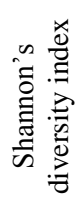 & 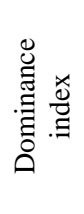 & 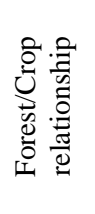 & 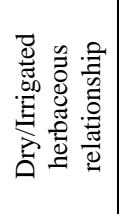 & 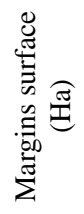 & 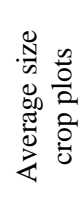 \\
\hline \multicolumn{8}{|l|}{ Forest dominated } \\
\hline Crop dominated & & & - & & & & \\
\hline \multicolumn{8}{|l|}{ Small crop plots } \\
\hline \multicolumn{8}{|l|}{ Large crop plots } \\
\hline \multicolumn{8}{|l|}{ Regular plots } \\
\hline \multicolumn{8}{|l|}{ Irregular plots } \\
\hline \multicolumn{8}{|l|}{ Monoculture } \\
\hline \multicolumn{8}{|l|}{ Diversity of crops } \\
\hline \multicolumn{8}{|c|}{ Presence of margins } \\
\hline \multicolumn{8}{|l|}{ Absence of margins } \\
\hline Shade of green & & & & + & & + & \\
\hline Shade of brown & & & & & & & \\
\hline
\end{tabular}




\section{DISCUSSION}

The study assessed aesthetic preferences towards the most representative agricultural uses in the study area and towards some aspects of agricultural landscape structure and composition. In both cases we found differences among respondent groups included in the sampling, meaning that significantly different ways of interacting with the landscape exist. The predefined groups have proven to be consistent because they have shown differentiated preferences (Pinto-Correia et al., 2011; Barroso et al., 2012). Regarding the aesthetic preferences towards agricultural uses, we found that the respondent groups ordered their aesthetic preferences differently, where farmers prefer irrigated herbaceous crops, local population prefers fruit trees, and tourists prefer grasslands. Sample locations of the locals and tourists do not have an effect on the visual preferences expressed by respondents. Regarding the aesthetic preferences towards agricultural landscape structure and compositions results, we found similar behavior among local residents and tourists, whereas farmers become a distinctive group with a high appreciation of farmland scenes (Van den Berg et al., 1998; Brusch et al., 2000). Preferences expressed by tourists and locals, specially locals from the biggest towns and tourists sampled in the Natural Park, show a high appreciation of landscape views common in multi-functional landscapes in rural areas, where farmland is in balance with the natural elements (Strumse, 1996; Arriaza et al., 2004; Rogge et al., 2007; Garcia-Llorente et al., 2012). Our results demonstrate a common demand among all respondent groups towards a traditional rural structuring (Nohl, 2001) when consensus for the presence of margins is expressed (García-Llorente et al., 2012; Claval, 2005). On the other hand, place characteristics where the sample took place (municipalities current residence size, natural park or beach) have an influence on the visual landscape preferences of respondents regarding agricultural landscape structures and compositions. Svobodova et al. (2011) and Strumse (1996) presented similar results that explained a gradient of the preferences from the rural to the urban environment.

Unlike Kaplan \& Kaplan (1989) we found only few results pointing towards the importance of landscapes familiar to the respondents (locals and farmers) in their landscape visual preferences. The findings show the positive influence of the high presence of olives and irrigated herbaceous crops on the aesthetic preferences of respondents to these agricultural uses, meaning that both uses awake a sense of identity. Our results suggest two types of influences from familiar landscapes of the respondents to their landscape structures and compositions visual preferences. On one side, a negative effect, where a reduction of crop diversity occurs; the greater the homogeneity of our agricultural landscape, the lower its perceived visual beauty of crop dominated landscapes. On the other side, a positive effect from the maintenance of natural features (forest and margins), as it increases the perception of wilderness in the landscape, and thus beauty preferences for shade of green landscapes. Our findings confirm other authors' suggestions, where there is a lower perception of visual beauty in homogeneous agrarian landscapes mainly due to the lack of color (Weinstoerffer \& Girardin, 2000; Arriaza et al., 2004), and a balance between human influence and nature (Strumse, 1994).

We found several significant relationships between socio-demographic characteristics of the respondents and their aesthetic preferences towards agricultural uses, but only age appears significant towards agricultural landscape structure and composition.

Among subcultural variables, age was a strong predictor of visual preference. On one hand, nut trees were more preferred by older respondents than by the younger ones, regardless that this land use was the least valued and the lesser present in the study area. On the other hand, younger respondents preferred non-cultivated landscapes, as Van den Berg et al. (1998) and Strumse (1996) found, explaining that naturalness contributes to landscape preference in 
Soy-Massoni E., Varga D., Sáez M., Pintó J.: Exploring aesthetic preferences in rural landscapes and the relationship with spatial pattern indices

a positive way. This could be interpreted as an expression of phytophilia (López-Santiago, 1994), which is the phenomenon of people generally preferring green, lush, forested vistas over arid landscapes (DeLucio \& Múgica, 1994).

Some weaknesses of the study methods should be noted. It might be argued that visual preferences obtained from colour photos and images limits generalization into real world settings. However, other studies have pointed out that the use of photographic representations yields valid and reliable results (Ulrich, 1979; Zube et al., 1987). We hope that this study and future work will help researchers assess the reliability of the visual perception method. Three potential limitations that should be taken into account in further applications of this approach: (1) we assumed that to use photos from different times of the year would be more realistic, (2) that exists a low familiarity against aerial images for the general public and the classical panoramatic views of landscape scenery would be more relevant, and (3) a photograph selection previous testing with potential interviewees and experts is needed.

\section{CONCLUSIONS}

We have implemented a straightforward method for assessing the visual quality of rural landscapes. The research design presented in this study is expected to contribute to improving the knowledge in landscape assessments through publicly expressed preferences and to the design of future agrarian landscapes. Mainly, our results highlight some differences in the visual landscape preferences among respondent groups, where farmers prefer agriculture dominated scenes while local residents and tourists prefer scenes with equilibrium between agricultural and natural elements. This shows that group differences in landscape preferences should not be neglected by landscape planners. On the other hand, presence instead of absence of margins is a common preference among the respondents, showing that participative landscape assessment is a powerful tool to identify common ground for consensus building and policy design. Place characteristic of the respondents explains aesthetic preferences among local residents living in municipalities of different population sizes, as well among tourists encountered either on the beach or in the Natural Park within the study area. The results also show a certain importance of familiarity and respondents' attachment to place in their landscape visual perceptions, suggesting that differences in landscape patterns may play a role in visual aesthetic quality, with both positive and negative effects. Certainly socio-demographic data of the respondents have an effect on their preferences, with age being a strong predictor of visual preference. Finally, we conclude that photos and aerial images were useful for the surrogates, although some improvements to the methods should take into account, e.g. using landscape photos from different times of the year.

\section{REFERENCES}

Arriaza, M., Canas-Ortega, J., Canas-Madueno, J., Ruiz-Aviles, P. (2004). Assessing the visual quality of rural landscapes. Landscape and Urban Planning, 69 (1), 115-125.

Barroso, F.L., Pinto-Correia, T., Ramos, I.L., Surová, S., Menezes, H. (2012). Dealing with landscape fuzziness in user preference studies: Photo-based questionnaires in the Mediterranean context. Landscape and Urban Planning, 104, 329- 342.

Bergen, S.D., Ulbricht, C.A., Fridley, J.L., Ganter, M.A. (1995). The validity of computer generated graphic images of forest landscapes. Journal of. Environmental Psychology. 15 
(2), 135-146.

Buijs, E., Pedroli, B., Luginbu, Y. (2006). From hiking through farmland to farming in a leisure landscape: Changing social perceptions of the European landscape. Landscape Ecology, 21, 375-389.

Bulut, Z., Yilmaz, H. (2008). Determination of landscape beauties through visual quality assessment method: A case study for Kemaliye (Erzincan/Turkey). Environmental Monitoring and Assessment, 141 (1), 121-129.

Bulut, Z., Yilmaz, H. (2009). Determination of waterscape beauties through visual quality assessment method. Environmental Monitoring and Assessment, 154 (1), 459-468.

Brush, R., Chenoweth, R. E., Barman, T. (2000). Group differences in the enjoyability of driving through rural landscapes. Landscape and Urban Planning, 47, 39-45.

Claval. P. (2005). Reading the rural landscapes. Landscape and Urban Planning, 70, 9-19.

Council of Europe. (1996). Pan-European biological and landscape diversity strategy. Nature and Environment. Council of Europe Press, Strasbourg.

Council of Europe. (2000). Landscape European convention. Council of Europe, Florence, Italy.

DeLucio, J. V., Múgica, M. (1994). Landscape preferences and behaviour of visitors to Spanish national parks. Landscape and Urban Planning, 29(2-3), 145-160.

García-Llorente, M., Martín-López, B., Iniesta-Arandia, I., López-Santiago, C. A., Aguilera, P. A. Montes, C. (2012). The role of multi-functionality in social preferences toward semi-arid rural landscapes: An ecosystem service approach. Environmental Science \& Policy, 19-20, 136-146.

Gobster, P. H., Nassauer, J. I., Daniel, T. C., Fry, G., (2007). The shared landscape: what does aesthetics have to do with ecology? Landscape Ecology, 22, 959-972.

de Val, G. D. L. F., Atauri, J. A., de Lucio, J. V. (2006). Relationship between landscape visual attributes and spatial pattern indices: a test study in Mediterranean-climate landscapes. Landscape and urban planning, 77(4), 393-407.

Hietala-Koivu, R. (1999) Agricultural landscape change: A case study in Ylane, southeast Finland. Landscape and Urban Planning, 46, 103-108.

Howley, P., Donoghue, C. O., Hynes, S. (2012). Exploring public preferences for traditional farming landscapes. Landscape and Urban Planning, 104, 66-74.

IDESCAT (2013). Institut d'Estadística de Catalunya. Retrieved January 3, 2013, from www.idescat.cat.

Kaplan, R., Kaplan, S. (1989). The Experience of Nature. A Psychological Perspective. Cambridge University Press, Cambridge.

Lindemann-Matthies, P., Briegel, R., Schüpbach, B., Junge, X. (2010). Aesthetic preference for a Swiss alpine landscape: The impact of different agricultural land-use with different biodiversity. Landscape and Urban Planning,98(2), 99-109.

Llausàs, A., Ribas, A., Varga, D., Vila, J. (2009). The evolution of agrarian practices and its effects on the structure of enclosure landscapes in the Alt Empordà (Catalonia, Spain), 19572001. Agriculture, Ecosystems \& Environment, 129, 73-82.

López-Santiago, C. (1994). Lo universal y lo cultural en la estética del paisaje. Un experimento transcultural de percepción del paisaje. Dissertation. Universidad Autónoma de Madrid, Madrid, Spain. 
Soy-Massoni E., Varga D., Sáez M., Pintó J.: Exploring aesthetic preferences in rural landscapes and the relationship with spatial pattern indices

McGarigal, K., Marks, B.J. (1994). FRAGSTATS_Spatial Analysis Program for Quantifying Landscape Structure. USDA Forest Service, General Technical Report PNW-GTR-351, Corvallis, OR.

McCullagh P, Nelder J. (1989). Generalized Linear Models. Second Edition. Boca Raton: Chapman and Hall/CRC.

Misgrav, A. (2000). Visual preference of the public for vegetation groups in Israel. Landscape and Urban Planning, 48, 143-159.

Nohl, W. (2001). Sustainable landscape use and aesthetic perception-preliminary reflections on future landscape aesthetics. Landscape and Urban Planning, 54, 223-237.

Pinto-Correia, T., Barroso, F., Surová, D., Menezes, H. (2011). The fuzziness of Montado landscapes: Progress in assessing user preferences through photo-based surveys. Agroforest Syst, 82, 209-224.

R Core Team. R. (2014). A language and environment for statistical computing. Vienna, Austria: R Foundation for Statistical Computing. Retrieved March 30, 2014, from URL http://www.r-project.org/.

Rogge, E., Nevens, F., Gulinck, H. (2007). Perception of rural landscapes in Flanders: Looking beyond aesthetics. Landscape and Urban Planning. 82, 159-174.

SIGPAC (2012). Departament d'Agricultura, Ramaderia, Pesca, Alimentació i Medi Natural, Generalitat de Catalunya.

Strumse, E. (1994). Environmental Attributes and the prediction of visual preferences for agrarian landscapes in Western Norway. Journal of Environmental Psychology, 14, 293-303.

Strumse, E. (1996). Demographic differences in visual preferences for agrarian landscapes in Western Norway. Journal of Environmental Psychology, 16, 17-31.

Sullivan, W. C., Anderson, O. M., Lovell, S. T. (2004). Agricultural buffers at the ruralurban fringe: an examination of approval by farmers, residents, and academics in the Midwestern United States. Landscape and Urban Planning, 69(2), 299-313.

Surová, D., Surovy, P., Almeida Ribero, N., Pinto-Correia, T. (2011). Integrating differentiated landscape preferences in a decision support model for the multifunctional management of the Montado. Agroforest Syst, 82, 225-237.

Svobodova, K., Vondrus, J., Filova, L., Besta, M. (2011). The role of familiarity with the landscape in visual landscape preferences. Journal of Landscape Studies, 4, 11-24.

Termorshuizen, J. Opdam, P. (2009). Landscape services as a bridge between landscape ecology and sustainable development. Landscape Ecol, 24, 1037-1052.

Ulrich, R. S. (1986). Human responses to vegetation and landscapes.Landscape and urban planning, 13, 29-44.

Van den Berg, A. E., Koole, S.L. (2006). New wilderness in the Netherlands: An investigation of visual preferences for nature development landscapes. Landscape and Urban Planning, 78, 362-372.

Van den Berg, A.E., Vlek, C.A.J., Coeterier, J.F. (1998). Group differences in the aesthetic valuation of nature development plans: A multilevel approach. J. Environ. Psycol. 18, 141157.

Walker, A.J., Ryan, R.L. (2008). Place attachment and landscape preservation in rural New England: A Maine case study. Landscape and Urban Planning, 86, 141-152. 
Weinstoerffer, J., Girardin, P. (2000). Assessment of the contribution of land use pattern and intensity to landscape quality: use of a landscape indicator. Ecol. Modell., 130, 95-109.

Zube, E.H., Sella, J.L., Taylor, J.G. (1982). Landscape perception: Research, application and theory. Landscape Planning, 9, 1-33.

\section{APPENDIX 1}

\begin{tabular}{|c|c|c|}
\hline Respondents' profile & $\mathbf{N}$ & $\%$ \\
\hline \multicolumn{3}{|l|}{ Origin } \\
\hline Local & 129 & 51.39 \\
\hline Girona region & 38 & 15.14 \\
\hline Rest of Catalonia & 63 & 25.10 \\
\hline Abroad & 21 & 8.37 \\
\hline \multicolumn{3}{|l|}{ Age } \\
\hline Adult (31-60 years old) & 166 & 66.14 \\
\hline Youth(18-30 years old) & 55 & 21.91 \\
\hline Elderly ( $>60$ years old) & 30 & 11.95 \\
\hline \multicolumn{3}{|l|}{ Education level } \\
\hline University degree & 94 & 37.45 \\
\hline Professional studies & 64 & 25.50 \\
\hline Basic studies & 84 & 33,47 \\
\hline No studies & 9 & 3,59 \\
\hline \multicolumn{3}{|l|}{ Gender } \\
\hline Male & 120 & 47.81 \\
\hline Female & 131 & 52.19 \\
\hline \multicolumn{3}{|l|}{ Farm relationship } \\
\hline Comes from farming family & 62 & 24.70 \\
\hline Does not come from farming family & 189 & 75.30 \\
\hline \multicolumn{3}{|l|}{ Environmental sensitivity } \\
\hline Member of an NGO & 14 & 5.58 \\
\hline No member of an NGO & 237 & 94.42 \\
\hline
\end{tabular}

